\title{
Erratum to: Charge effect of superparamagnetic iron oxide nanoparticles on their surface functionalization by photo-initiated chemical vapour deposition
}

\section{Taraneh Javanbakht • Sophie Laurent • Dimitri Stanicki • Wendell Raphael • Jason Robert Tavares}

Published online: 7 November 2016

C Springer Science+Business Media Dordrecht 2016

Erratum to: J Nanopart Res 17:462 (2015). DOI:10.1007/s11051-015-3276-y

A calibration error on our radiometer led us to misreport irradiance values for the UVC lamps used in our original manuscript.

The original statement:

"The precursor gas mixture $\left(\mathrm{H}_{2}\right.$ and $\left.\mathrm{CO}\right)$ was injected in the reactor with a molar ratio of $0.1 / 1$
$\left(\mathrm{H}_{2} / \mathrm{CO}\right)$ and was irradiated by two UVC lamps (main emission peak at $253.7 \mathrm{~nm}$, irradiance of $5.5 \times 10^{-4} \mathrm{~W} / \mathrm{cm}^{2}$ at $\left.4.5 \mathrm{~cm}\right)$."

The corrected statement:

"The precursor gas mixture $\left(\mathrm{H}_{2}\right.$ and $\left.\mathrm{CO}\right)$ was injected in the reactor with a molar ratio of $0.1 / 1$ $\left(\mathrm{H}_{2} / \mathrm{CO}\right)$ and was irradiated by two UVC lamps (main emission peak at $253.7 \mathrm{~nm}$, irradiance of $0.01 \mathrm{~W} / \mathrm{cm}^{2}$ at $\left.3.5 \mathrm{~cm}\right)$."

The online version of the original article can be found at http://dx. doi.org/10.1007/s11051-015-3276-y

T. Javanbakht $\cdot$ W. Raphael $\cdot$ J. R. Tavares $(\bowtie)$

Department of Chemical Engineering, Ecole Polytechnique of

Montreal, Montreal, QC H3C 3A7, Canada

e-mail: jason.tavares@polymtl.ca

S. Laurent $\cdot$ D. Stanicki

Laboratory of NMR and Molecular Imaging, University of Mons, Avenue Maistriau 19, 7000 Mons, Belgium

S. Laurent

Center for Microscopy and Molecular Imaging (CMMI),

6041 Gosselies, Belgium 